\title{
Correction to: Laparoscopic and open surgery in rectal cancer patients in Germany: short and long-term results of a large 10-year population- based cohort
}

\author{
Valentin Schnitzbauer ${ }^{1} \cdot$ Michael Gerken $^{2}\left(D \cdot\right.$ Stefan Benz ${ }^{3} \cdot$ Vinzenz Völkel $^{2} \cdot$ Teresa Draeger $^{2} \cdot$ Alois Fürst $^{4}$. \\ Monika Klinkhammer-Schalke ${ }^{2,5}$
}

Published online: 19 September 2019

(c) The Author(s) 2019

\section{Correction to: Surgical Endoscopy https://doi.org/10.1007/s00464-019-06861-4}

The article, "Laparoscopic and open surgery in rectal cancer patients in Germany: short and long-term results of a large 10-year population-based cohort," written by Valentin Schnitzbauer, Michael Gerken, Stefan Benz, Vinzenz Völkel,, Teresa Draeger, Alois Fürst, and Monika Klinkhammer-Schalke was originally published electronically on the publisher's internet portal (currently SpringerLink) on 30 May 2019 without open access.

With the author(s)' decision to opt for Open Choice the copyright of the article changed on September 18, 2019 to (C) The Author(s) 2019 and the article is forthwith distributed under the terms of the Creative Commons Attribution 4.0 International License (http://creativecommons.org/licenses/ by/4.0/), which permits use, duplication, adaptation, distribution and reproduction in any medium or format, as long as you give appropriate credit to the original author(s) and

The original article can be found online at https://doi.org/10.1007/ s00464-019-06861-4.

\author{
Michael Gerken \\ michael.gerken@ur.de \\ Valentin Schnitzbauer \\ valentin.adrian@schnitzbauer.eu \\ Stefan Benz \\ s.benz@klinikverbund-suedwest.de \\ Vinzenz Völkel \\ vin.voelkel@posteo.de \\ Teresa Draeger \\ teresa.draeger@gmx.de \\ Alois Fürst \\ afuerst@caritasstjosef.de \\ Monika Klinkhammer-Schalke \\ monika.klinkhammer-schalke@ur.de
}

the source, provide a link to the Creative Commons license and indicate if changes were made.

Publisher's Note Springer Nature remains neutral with regard to jurisdictional claims in published maps and institutional affiliations.
1 Faculty of Medicine - University Hospital Regensburg, University of Regensburg, Franz-Josef-Strauß-Allee 11, 93053 Regensburg, Germany

2 Tumor Center Regensburg, Institute for Quality Assurance and Health Services Research, University of Regensburg, Am BioPark 9, 93053 Regensburg, Germany

3 Klinik für Allgemeine-, Viszeral- und Kinderchirurgie, Kliniken Böblingen, Bunsenstr. 120, 71032 Böblingen, Germany

4 Department of Surgery, Caritas Clinic St. Josef, Landshuter Strasse 65, 93053 Regensburg, Germany

5 Arbeitsgemeinschaft Deutscher Tumorzentren e.V., Kuno-Fischer-Strasse 8, 14057 Berlin, Germany 